\title{
UTOPIA E CIDADE: O ESPAÇO URBANO COMO ELEMENTO DE TRANSFORMAÇÃO SOCIAL
}

\author{
UTOPIA AND CITY: URBAN SPACE AS ELEMENT OF SOCIAL
} TRANSFORMATION

\section{Jacques Felipe latchuk Vieira ${ }^{1}$ Ana Beatriz Cruz Nunes ${ }^{2}$}

ISSUE DOI: $10.21207 / 1983.4225 .362$

\section{RESUMO}

A cidade, como é conhecida hoje, é estruturada sob a lógica de reprodução do capital, orientada para os interesses do mercado e marcada pela forte presença de um projeto urbano que cumpre a função não só de precarização das condições de vida e de reprodução da classe trabalhadora, mas também de tolhimento do espírito revolucionário dessa classe. Sendo assim, por entender a apropriação do espaço urbano dentro da conjuntura atual como algo revolucionário, busca-se analisar, no presente trabalho, como o processo de formação das cidades na modernidade e na pós-

\footnotetext{
${ }^{1}$ Graduando em Direito pela Universidade Estadual Paulista (UNESP). Autor de artigos acadêmicos.

${ }^{2}$ Graduanda em Direito pelo Faculdade de Ciências Humanas e Sociais (UNESP/ Câmpus de Franca). É bolsista de iniciação científica pela Fundação de Amparo à Pesquisa do Estado de São Paulo (FAPESP) e Representante Discente do Conselho de Curso de Direito. Foi monitora das disciplinas de Sociologia e Sociologia do Direito na Universidade Estadual Paulista Júlio de Mesquita Filho e educadora popular no cursinho de popular S.E.U (Serviço de Extensão Universitária). Atua no Núcleo de Estudos de Direito Alternativo (NEDA), no grupo de extensão Assessoria Jurídica Popular (AJUP) e no grupo de pesquisa Estudos em Direito e Mudança Social (DEMUS).
} 
modernidade está ligado a um conjunto de medidas que procuraram garantir a perpetuação da lógica capitalista. Também, entender quais instrumentos do Direito à Cidade podem influenciar na mudança do paradigma atual de cidade.

Palavras-chave: Direito à Cidade. Planejamento Urbano. Utopia e Marxismo.

\section{ABSTRACT}

Abstract: The city as we know it today is structured under the logic of reproduction of capital, oriented to the interests of the market and marked by the strong presence of an urban project that fulfills the function not only of precariousness of the conditions of life and reproduction of the class Working class, but also to hinder the revolutionary spirit of this class. Therefore, because we understand the appropriation of urban space within the current conjuncture as something revolutionary, we will try to analyze, in the present work, how the process of formation of cities in modernity and postmodernity is linked to a set of measures that sought to guarantee the Perpetuation of capitalist logic. Also, to understand which instruments of the Right to the City can influence in the change of the current paradigm of city.

Keywords: Right to the City. Urban planning. Utopia and Marxism.

\section{INTRODUÇÃO}

Na pós-modernidade a cidade não é mais concebida enquanto espaço rigidamente estratificado por ocupação e classe, mas sim marcada pelo individualismo, no qual a distinção social é assinalada através da posse e do consumo, configurando pois, a cidade enquanto sistema racionalizado e automatizado de produção e consumo de massa de bens materiais. Uma vez que a cidade não é mais entendida enquanto comunidade de pessoas, mas sim como um labirinto ou rede de diversas interações sociais orientada para as metas e objetivos do capital, a cidade é demasiada complexa para ser concebida apenas a partir do totalitarismo dos planejadores, dos burocratas e das elites corporativas. Estas devem ser compreendidas enquanto espaço de sujetificação e de construção do ser social. 
Se, por um lado moldamos a cidades a nossa imagem, "elas, por sua vez, nos moldam por meio da resistência que oferecem quando tentamos impor-lhes nossa própria forma pessoal" 3 . Isso demarca que existe uma relação peculiar entre o homem e o conteúdo que existe na contínua interação criativa da vida urbana, o que traz à tona a questão de como a cidade interfere não apenas na nossa subjetividade, mas na nossa sujetificação enquanto seres sociais.

O marco histórico das cidades na pós-modernidade é a década de 1970 por conta dos movimentos artísticos e culturais que influenciaram toda a arquitetura pós-moderna e o ideário do pós-guerra; mas também as questões econômicas e sociais que provocaram importantes mudanças na qualidade de vida urbana nesse contexto histórico.

Se, por um lado, o ideário da cultura e da arquitetura na pósmodernidade é o de "abraçar imprudentemente a linguagem do comércio e da mercadoria"4, construiu-se a crítica de que o Modernismo era um movimento positivista, tecnocêntrico e racionalista em razão da defesa da concepção do progresso linear, cujos reflexos foram o planejamento racional de ordens sociais, a padronização do conhecimento e da produção.

Construiu-se, por outro lado, o ideário de que o pós-moderno privilegia a heterogeneidade e a diferença como forças libertadoras na redefinição do discurso cultural. A fragmentação, a indeterminação e a desconfiança de todos os discursos universais e totalizantes são o marco do pensamento pós-moderno, dentro até mesmo da ideia de que não há uma história universal. É a partir dessas concepções que surge o gérmen da critica do materialismo histórico e dialético, legitimado, pois, pelo discurso da fragmentação, da heterogeneidade e da liquidez das relações econômicas e sociais. Sempre tendo em mente as palavras de Robert Park, quando diz que a cidade é:

[...] a mais consistente e, no geral, a mais bemsucedida tentativa do homem de refazer o mundo onde vive de acordo com o desejo de seu coração. Porém, se a cidade é o mundo que o homem criou, então é nesse mundo que de agora em diante ele está condenado a viver. Assim, indiretamente, e sem

\footnotetext{
${ }^{3}$ RABAN, Jonathan. Soft city. Londres: 1974, p. 9-10.

${ }^{4}$ EAGLETON, T. "Awakenig from modernity", Times Literary Suplement, 20 de fevereiro de 1987. p. 21.
} 
nenhuma ideia clara da natureza de sua tarefa, ao fazer a cidade, o homem refez a si mesmo. ${ }^{5}$

\section{A CIDADE NA PÓS-MODERNIDADE: ARQUITETURA E PROJETO URBANO}

Enquanto os projetistas e arquitetos modernistas veem o espaço como algo a ser pensado para a realização de propósitos sociais, ou seja, a partir da perspectiva da construção de um projeto social, os pósmodernistas o veem como algo autônomo ser moldado segundo objetivos estéticos independentemente de qualquer reação ou objetivo sociais.

Dentre as razões para isso destaca-se a questão de que o ambiente constitui um elemento de um complexo de experiência urbana que é fundamental na construção de novas sensibilidades culturais. Ou seja, está ligado à construção da subjetividade das pessoas.

A aparência de uma cidade e o modo como os seus espaços se organizam formam uma base material a partir da qual é possível pensar, avaliar e realizar uma gama de possíveis sensações e práticas sociais ${ }^{6}$.

Resta, portanto o questionamento dos motivos pelos quais esse tipo de organização urbana e de planejamento das cidades tornou-se dominante no pós-guerra. Os problemas políticos, econômicos e sociais enfrentados pelos países capitalistas posteriormente à Segunda Guerra Mundial necessitavam de algum programa que atendesse aos anseios sociais por uma perspectiva possível de "mundo melhor", tudo isso em razão da transformação do ideário das pessoas frente aos reflexos da barbárie da guerra. Para que se mantivessem democráticas e para que garantissem a reprodução capitalista, as políticas públicas do pós-guerra tinham que tratar das questões de emprego, moradia digna, bem-estar social,

\footnotetext{
${ }^{5}$ PARK, Robert. On Social Control and Collective Behavior. Chicago, Chicago University Press, 1967, p. 3.

${ }^{6}$ HARVEY, David. Condição pós-moderna (1989). São Paulo: Loyola, 1993, p. 69.
} 
recuperação econômica, entre outros. Inicia-se, a partir de então, um amplo processo em massa de reconstrução e de reorganização das cidades.

Dentro desse contexto, a reconstrução e a renovação do tecido urbano se tornaram pontos fulcrais desse projeto. A partir daí, surgem os debates da legislação municipal e nacional das cidades ( com as quais pode ser feito um paralelo, atualmente, com os Planos Diretores e o Estatuto da Cidade), e a questão do planejamento urbano racional (ligada, atualmente, às questões da mobilidade urbana, da segregação social da classe trabalhadora na periferia da periferia, a higienização social, entre outras). Ainda, nesse contexto, a construção industrializada ganha destaque com preocupações, a partir desse marco, expressas na própria legislação.

Deve-se destacar, ainda, que tudo isso se deu apoiado na produção em massa, nos sistemas de construção industrializados e na concepção de se fazer emergir um espaço urbano racionalizado. Inclusive, dentro dessa discussão, insere-se a questão da prorrogação e ampliação das formas individualizadas de transporte, construídas através da própria infraestrutura fornecida pelo Estado (avenidas, vias expressas, etc.).

Essas medidas tiveram êxito em reconstruir o tecido urbano de modo a preservar o pleno emprego, a melhorar os equipamentos urbanos, e a contribuir com a política de bem-estar social, facilitando, portanto, a preservação da ordem econômica e social capitalista ameaçada com a Segunda Guerra Mundial. Mas também, é necessário discutir quais foram os desdobramentos desses projetos na contemporaneidade.

$\mathrm{Na}$ atual conjuntura, a especulação imobiliária tornou-se um dos principais setores de acumulação do Capital. Em relação à questão do tempo-espaço, podemos dizer que na pós-modernidade, as formas de organização das cidades visando à garantia da reprodução capitalista, exigiu projetos urbanos mais diversificados, com formas urbanas mais dispersas, descentralizadas e desconectadas. Sendo assim, a mobilidade urbana demanda tecnologias de transporte capazes de atender as necessidades de interesse social, o que é algo muito complexo na realidade das cidades brasileiras.

Para se pensar alguma possibilidade de superação desse paradigma das cidades orientadas para o mercado, deve-se pensar como superar a influência política e o poder do mercado na determinação dos rumos das políticas públicas de planejamento urbano. Aí reside o ponto fulcral para a mudança de paradigmas, ou seja, a disputa de hegemonia. Tal con- 
ceito foi resgatado do pensamento de Bourdieu por Harvey (1989) ao destacar que:

A produção do capital simbólico serve a funções ideológicas porque os mecanismos por meio dos quais ela contribui 'para a reprodução da ordem estabelecida e para a perpetuação da dominação' permanecerem ocultos. ${ }^{7}$

Sendo assim, é necessário debater não somente qual cidade ou planejamento urbano se quer conquistar, mas quais perspectivas de apropriação do espaço público abrem caminho a um novo paradigma de cidade. Uma vez que ao construirmos perspectivas de projeto democrático de planejamento urbano é inevitável a discussão de quais direitos e por quais políticas públicas devemos lutar e, consequentemente, faz-se necessário o debate de qual conjunto de direitos entendemos como constitutivos do "Direito à cidade". Nas palavras de David Harvey,

O direito a cidade não pode ser concebido como um simples direito de visita ou a um retorno as cidades tradicionais. Ao contrário, ele pode apenas ser reformulado como um renovado e transformado direito à vida urbana. ${ }^{8}$

\section{A REFORMULAÇÃO DOS ESPAÇOS PÚBLICO E PRIVADO}

Para que seja possível entender mais a fundo a questão da cidade, na forma como está moldada pelo capitalismo neoliberal, enquanto espaço que se estrutura para tolher o espírito revolucionário da classe trabalhadora, faz-se importante um olhar mais atento sobre a reformula-

\footnotetext{
${ }^{7}$ HARVEY, David. Condição pós-moderna (1989). São Paulo: Loyola, 1993. p. 81.

${ }^{8}$ HARVEY, David. A liberdade da cidade. Cidades Rebeldes: Passe Livre e as manifestações que tomaram as ruas do Brasil. 1. ed. São Paulo: Boitempo: Carta Maior, 2013, p. 28.
} 
ção da lógica dos espaços públicos e privados, e, de forma acentuada, a mudança do papel da moradia nesse quadro.

O desenvolvimento histórico do capitalismo fez com que as cidades cada vez mais fossem pensadas para favorecer o capital. Dessa forma, progressivamente os espaços públicos foram sendo tomados por interesses de poucos particulares, sempre tendo em vista não apenas a manutenção do sistema vigente, mas também o aprofundamento das diferenças de classe e a radicalização da concentração de renda. O exemplo mais evidente desse fato é o planejamento urbano de Georges-Eugène Haussmann, por ordens de Napoleão III, para a dita modernização de Paris, a partir da segunda metade do século XIX, e que se apresentou como o grande referencial de como lidar com a questão urbana para todo o mundo ocidental até a segunda metade do século XX.

Hausmann, por meio de seu projeto para um novo período da capital francesa, não se limitou a reestruturar a lógica das ruas fisicamente: através das reformas postas, catalisou a tomada de consciência daquilo que Walter Benjamin assinala como "o caráter desumano da grande metrópole" " A modernização de Paris reforçava de maneira até então nunca vista a lógica da segregação urbana e da cidade enquanto instrumento a serviço do capital. Para compreender tal afirmação, são necessárias as análises de dois aspectos diferentes (mas que se põem, em fundo, por uma mesma causa) desse projeto: a) o aspecto físico das mudanças e b) o aspecto econômico que motiva a reorganização.

No que tange as mudanças físicas planejadas por Haussmann, para além da necessidade de trazer mais prestígio ao governo golpista de Napoleão III com grandes eventos de inaugurações de obras que poderiam parecer meramente técnicas (dando um novo caráter artístico a estas), o objetivo principal era impedir ao máximo a viabilidade física de barricadas e demais instrumentos de resistência da população em casos de novas revoltas populares, ao passo que também iniciava um processo mais acentuado de marginalização das classes trabalhadoras e de segregação urbana. Assim, a própria organização do espaço urbano serviria como arma de manutenção do governo e do sistema postos contra quaisquer

\footnotetext{
${ }^{9}$ BENJAMIN, Walter. Paris, Capital do Século XIX. In Textos de Walter Benjamin. Trad. Flavio R. Kothe. p. 41. Disponível em: $<$ https://teoriadoespacourbano.files.wordpress.com/2013/03/benjamin-w-pariscapital-do-sc3a9culo-xix-trad-kothe.pdf >.
} 
manifestações mais violentas por parte das classes oprimidas, assim como de reafirmação da diferença de classes. Benjamin confirma isso ao dizer:

\begin{abstract}
A verdadeira finalidade das obras de Haussmann era tornar a cidade segura em caso de guerra civil. Ele queria tornar impossível que no futuro se levantassem barricadas em Paris. (...) Haussmann quer impedi-las de duas maneiras: a largura das avenidas deveria tornar impossível erguer barricadas e novas avenidas deveriam estabelecer um caminho mais curto entre as casernas e os bairros operários. Os contemporâneos batizam esse empreendimento de embelissement stratégique [embelezamento estratégico]. ${ }^{10}$
\end{abstract}

Ao mesmo tempo, as transformações da cidade tiveram em seu cerne uma profunda influência da situação econômica pela qual atravessava a França no dado período. Era preciso que surgisse algum fator novo que pudesse dar conta tanto do capital excedente ocioso quanto da grave crise de desemprego que atingia toda a Europa, principalmente a partir de 1848 , o que foi conseguido por meio desse contundente investimento em grandes obras de infraestrutura, tanto interna quanto externamente. $\mathrm{Ou}$ seja, o processo conduzido por Haussmann conseguiu dar emprego à classe trabalhadora desempregada ao fazê-la construir os monumentos que eram financiados pelo excedente de capital ocioso que havia.

No entanto, essa solução "mágica" de Haussmann não consegue resolver o problema de forma definitiva. Pelo contrário, apenas faz com que sejam necessárias novas reformas urbanas ainda mais violentas, já que as anteriores resultam também na geração de um excedente de capital ocioso, e apenas transferem a pobreza e a falta de estrutura urbana para outras localidades. Sobre isso, Engels aponta brilhantemente:

$\mathrm{Na}$ realidade, a burguesia só tem um método para resolver a questão da moradia do seu jeito - isto é,

\footnotetext{
${ }^{10}$ Benjamin, Walter. Paris, Capital do Século XIX. In Textos de Walter Benjamin. Trad. Flavio R. Kothe. p. 41. Disponível em: $<$ https://teoriadoespacourbano.files.wordpress.com/2013/03/benjamin-w-pariscapital-do-sc3a9culo-xix-trad-kothe.pdf >.
} 
resolvê-la de tal maneira que a solução sempre volta a suscitar o problema. Esse método se chama de Haussmann. (...) Os focos de epidemias, as covas e os buracos mais infames em que o modo de produção capitalista trancafia nossos trabalhadores noite após noite não são eliminados, mas apenas transferidos para outro lugar! A mesma necessidade econômica que os gerou no primeiro local também os gerará no segundo. ${ }^{11}$

De maneira impressionante, esse processo cíclico de reformas urbanas em defesa da burguesia continuou ocorrendo por todos os principais pontos do mundo ocidental, mesmo que sofrendo pequenas reformulações táticas de tempos em tempos, sem, com isso, perder sua essência haussmanniana ${ }^{12}$. Dentre as citadas reformulações táticas ocorridas, fazse importante ressaltar a centralidade que Robert Moses (que comandou um processo parecido ao de Haussmann na Nova York da década de 1940) deu à questão da casa própria, ao passo que realizou intensa suburbanização da metrópole, e os efeitos que isso teve na organização da sociedade a partir de tal momento.

A partir do momento em que entra em cena a casa própria subsidiada para a classe média, o panorama político é alterado. Isso porque ocorre uma mudança no foco dessa parcela da população, que coloca em segundo plano as ações em comunidade para dar prioridade a questões de âmbito mais individualista, como a defesa da propriedade privada e das identidades individualizadas, o que acaba por propagar de forma mais facilitada o conservadorismo entre essa parcela. Quando se conquista um elemento de diferenciação clara das classes mais baixas e que se faz tão importante para a organização do núcleo familiar e da vida privada, como a casa própria, acaba por haver um recuo na disposição em participar de movimentações que exigem mudanças mais radicalizadas (como, por exemplo, greves), já que ao mesmo tempo há melhor condição de vida e mais a arriscar participando de tais movimentações. Isso é um dos fatores que ajuda a entender, por exemplo, a reorganização do voto dessa classe

${ }^{11}$ ENGELS, Friedrich. Sobre a Questão da Moradia. $1^{\mathrm{a}}$ ed. São Paulo: Boitempo Editorial. 2015, p. 104-108.

${ }^{12}$ HARVEY, David. O Direito à Cidade. In Revista Lutas Sociais. São Paulo, $\mathrm{n}^{\circ}$ 29. 
em direção do Partido Republicano, nos EUA ${ }^{13}$. Com tal processo, conseguiu-se que a casa própria se tornasse mais um dos elementos da estrutura urbana a servirem como instrumento para a desmobilização política da classe trabalhadora. Reitera-se, portanto, também por meio da oferta de moradia, a cidade enquanto espaço de constante defesa do capitalismo ${ }^{14}$.

No entanto, há também outra perspectiva de análise a respeito da questão da moradia que se faz necessária para que seja possível entender de forma mais completa seu papel no ambiente capitalista atual, radicalizado pela pós-modernidade e pelo avanço brutal do neoliberalismo nas últimas décadas.

A partir de certo momento do desenvolvimento da humanidade, ocorreu uma alteração na forma como a moradia era concebida, alteração que se fez mais intensa a partir da ascensão do capitalismo como forma estabelecida de civilização. Os espaços de habitação coletiva (onde moravam e conviviam diuturnamente diferentes pessoas e famílias) foram sendo cada vez mais postos de lado em favor da busca pelo lar familiar. Ou seja, houve uma mudança na concepção da habitação, que abandona o caráter mais "público" e de grande interação social para dar prioridade a uma visão mais intimista e particular de moradia, que vai cada vez mais se restringindo a uma quantidade menor de pessoas. Até chegar ao modelo predominante hoje em dia, no qual as casas se fazem habitadas por um núcleo familiar bastante reduzido ou, até mesmo, por apenas um indivíduo $^{15}$. Não se pode, no entanto, deixar de mencionar que esse processo, assim como grande parte das mudanças comportamentais da sociedade, se deu "de cima para baixo", sendo conduzida em primeiro momento pelas classes mais abastadas. Isso tem muito a ver com o fato de a moradia adquirir cada vez mais forte o caráter de mercadoria, que evidencia status

${ }^{13}$ HARVEY, David. O Direito à Cidade. In Revista Lutas Sociais. São Paulo, $\mathrm{n}^{\circ} 29$. p. 120.

${ }^{14}$ HARVEY, David. O Trabalho, o capital e o conflito de classes em torno do ambiente construído nas sociedades capitalistas avançadas. In Temas Urbanos e Regionais. p. 13-14 Disponível em: <https://antropologiadeoutraf orma.files.wordpress.com/2014/03/david-harvey-o-trabalho-o-capital-e-harveydavid-o-conflito-de-classes-em-torno-do-ambiente-construc3addo-nassociedades-capitalistas-avanc3a7adas.pdf $>$.

${ }^{15}$ ROLNIK, Raquel. O Que é Cidade. São Paulo: Editora Brasiliense. 1988. p. 48-49. 
social (principalmente quanto maior a relação inversamente proporcional entre o tamanho da habitação e a quantidade de habitantes).

Por isso, a moradia (enquanto espaço concebido para o abrigo e o relacionamento particular entre familiares, mas também como fonte de maior status social) se coloca como elemento indispensável de ser analisado, para que seja possível entender as movimentações do capitalismo, pela influência que passou a exercer sobre a organização social dos cidadãos, principalmente devido ao fato de, com o passar do tempo, ser cada vez mais fulcral no que diz respeito à formação da identidade e da individualidade das pessoas. E, novamente, serve para reforçar e explicar a tese do conservadorismo gerado pela suburbanização implementada por Moses nos EUA da década de 1940.

Com essa mudança de caráter da habitação, esse espaço vai se tornando cada vez mais o local principal da vida privada do indivíduo, em contraposição ao espaço público da rua e o espaço de dominação do capital que é o ambiente de trabalho.

Pela primeira vez, o espaço em que vive o homem privado se contrapõe ao local de trabalho. Organizase no interior da moradia. O escritório é seu complemento. $\mathrm{O}$ homem privado, realista no escritório, quer que o interieur sustente as suas ilusões. Esta necessidade é tanto mais aguda quanto menos ele cogita estender os seus cálculos comerciais às suas reflexões sociais. Reprime ambas ao confirmar o seu pequeno mundo privado. Disso se originam as fantasmagorias do "interior", da interioridade. Para o homem privado, o interior da residência representa o universo. Nele se reúne o longínquo e o pretérito. O seu salon é um camarote no teatro do mundo. [...] o centro de gravidade do espaço existencial se desloca para o escritório. O seu contraponto, esvaziado de realidade, constrói seu refúgio no lar. ${ }^{16}$

16 Benjamin, Walter. Paris, Capital do Século XIX. In Textos de Walter Benjamin. Trad. Flavio R. Kothe. p. 37-38. Disponível em: <https://teoriadoes pacourbano.files.wordpress.com/2013/03/benjamin-w-paris-capital-dosc3a9culo-xix-trad-kothe.pdf> 
Ao mesmo tempo, em decorrência da modernidade, levada a cabo pelo projeto de urbanismo de Haussmann, começa a haver uma tomada cada vez maior do caráter público das ruas pelo domínio e pela lógica destruidora do capital. Uma característica muito relevante dessa alteração, qual seja, a destruição da aura da obra de arte em decorrência da "velocidade" da modernidade, foi brilhantemente exposta por Baudelaire em um de seus pequenos textos, Perda da Auréola, que posteriormente é analisado por Benjamin. Trata-se de um diálogo entre o poeta (que representa ali o próprio Baudelaire) e um passante que o reconhece mesmo em meio ao caos urbano. Tendo isso em vista, o diálogo se dá nos seguintes termos:

Ora, ora, meu caro! O senhor! Aqui! Em local mal afamado - um homem que sorve essências, que se alimenta de ambrosia! De causar assombro, em verdade. - Meu caro, sabe do medo que me causam cavalos e veículos. Há pouco estava eu atravessando o bulevar com grande pressa, e eis que, ao saltar sobre a lama, em meio a este caos em movimento, onde a morte chega a galope de todos os lados ao mesmo tempo, minha auréola, em um movimento brusco, desliza de minha cabeça e cai no lodo do asfalto. Não tive coragem de apanhá-la. Julguei menos desagradável perder minhas insígnias do que me deixar quebrar os ossos. E agora, então, disse a mim mesmo, o infortúnio sempre serve para alguma coisa. Posso agora passear incógnito, cometer baixezas e entregar-me às infâmias como um simples mortal! Eis-me, pois, aqui, idêntico ao senhor, como vê! [...] Além disso apraz-me o pensamento que um mau poeta qualquer a apanhará e se enfeitará com ela, sem nenhum pudor. Fazer alguém ditoso - que felicidade! Sobretudo alguém que me fará rir! Imagine X ou Y! Não, isto será burlesco! ${ }^{17}$

\footnotetext{
${ }^{17}$ BENJAMIN apud SANTOS NETO, Artur Bispo dos. A Interpretação Alegórica do mundo na Filosofia de Walter Benjamin. Disponível em: $<$ https://books.google.com.br/books?id=Hm87AsJwPxgC\&printsec=frontcover\& $\mathrm{hl}=\mathrm{pt}-\mathrm{BR} \&$ source $=\mathrm{gbs} \_\mathrm{ge} \_$summary_r$\& \mathrm{cad}=0 \# \mathrm{v}=$ onepage $\& \mathrm{q} \& \mathrm{f}=$ false $>$. p. 23 .
} 
A modernidade, assim, traz estímulos cada vez maiores e mais rápidos, e que são catalisados pela pós-modernidade, de forma que se fazem quase incessantes no mundo atual (não só pelos automóveis mais velozes das ruas, mas também pelo excesso constante de propagandas e a demanda inesgotável de atenção por meio de celulares, smartphones e tablets). Isso gera uma necessidade de um permanente "estado de atenção" das pessoas, que sempre têm de estar prontas a raciocinar mais e mais para seguirem suas vidas. Por consequência, há um empobrecimento das funções pré-conscientes, como a própria criatividade (e, com ela, a capacidade de pensar a transformação); assim, há a morte da aura.

Maria Rita Kehl apresenta a hipótese ${ }^{18}$ de que o elemento que se apresenta para tomar o lugar da aura do poeta no espaço das ruas cheias e velozes da modernidade é o fetiche. Comprova-se isso ao verificar que não é possível transitar pelo ambiente urbano de cidades desenvolvidas, em qualquer lugar do mundo, sem ser absolutamente "bombardeado" pelos mais diversos meios de propagação e reiteração da lógica do capital: anúncios comerciais que buscam seduzir a população para adquirir algum serviço (com destaque para a utilização de famosos nesses anúncios, a fim de introduzir no subconsciente da população que haverá uma aproximação subjetiva à posição daqueles caso o serviço seja adquirido); vitrines que expõem diversos produtos (em geral totalmente desnecessários à vida do trabalhador) a serem adquiridos para provar uma aparência de ascensão no status social. O capital exige uma constância tão incessante de propagação do modo de civilização atual que até os meios de transporte coletivos (inclusive quando são públicos) são tomados pelo marketing inexaurível. Vide a presença certa em ônibus e metrôs de televisões com "programação especial" e quantidades assustadoras de banners, placas e plotagens de publicidade.

Essa constatação mostra que houve uma nova reformulação das lógicas espaciais dentro da cidade. $\mathrm{O}$ capitalismo não restringiu o seu domínio sobre o espaço de trabalho, mas aos poucos foi tomando, também, o espaço das ruas, de forma a reduzir cada vez mais a interação e a lógica do público nesse local. Estabeleceu-se, assim, no espaço das ruas, uma razão artificial de dominação planejada para reforçar e manter o capitalismo. Faz-se como a realidade artificial de Matrix (1999), arquite-

${ }^{18}$ Maria Rita Kehl: Por uma cidade sem carros! - Durante o seminário Cidades Rebeldes. Disponível em: <https://www.youtube.com/watch?v=28Mf1 nO2kYY>. Acesso em 12 mai. 2016. 
tada exclusivamente a fim de servir como grande instrumento de manutenção da dominação das máquinas sobre os humanos, sem que estes percebam que vivem sob tal espectro.

Chegando ao ponto de, como será melhor explicado no próximo capítulo, na pós-modernidade, associado ao processo radicalizado de segregação espacial que se deu em todo o período posterior a Haussmann, estabelecer o espaço das ruas como de domínio quase exclusivo da mentalidade do capital, não sendo mais sinônimo de confraternização ou mesmo interação pública. Raquel Rolnik explica:

Para a burguesia, o espaço público deixa de ser a rua - lugar das festas religiosas e cortejos que engloba a maior variedade possível de cidades e condições sociais - e passa a ser a sala de visitas, ou o salão. ${ }^{19}$

Dessa forma, acaba por ocorrer uma desumanização das pessoas e é reforçado o regime pós-moderno de individualismo autocentrado das pessoas, seguindo o fundamento alienante do capital, também pela reelaboração da cidade. Atinge-se, assim, o que demonstra novamente como estava correto Robert Park ao afirmar que ao alterarmos a cidade estamos modificando a nós mesmos.

\section{O ELEMENTO SUBJETIVO DA SEGREGAÇÃO ESPACIAL}

As cidades são o principal espaço de reprodução da força de trabalho; no entanto, seu papel não está restrito apenas ao fornecimento do lugar (o "chão") onde se concretiza a reprodução social do capital; as cidades, a partir das características ligadas, principalmente, ao planejamento urbano, também definem a forma como essa reprodução se dará.

As cidades são também um "grande negócio". Segundo Ermínia Maricato,

${ }^{19}$ ROLNIK, Raquel. O Que é Cidade. São Paulo: Editora Brasiliense. 1988, p. 49. 
Ela (a cidade) é um produto ou, em outras palavras, também um grande negócio, especialmente para os capitais que embolsam, com sua produção e exploração, lucros, juros e rendas. Há uma disputa básica, como um pano de fundo, entre aqueles que querem dela melhores condições de vida e aqueles que visam apenas extrair ganhos. ${ }^{20}$

As cidades constituem um complexo urbano construído histórica e socialmente, sendo sua apropriação, notadamente, desigual; portanto, é inerente às cidades a relação dialética entre os interesses das classes sociais. Em outras palavras, a cidade é um espaço de disputa de classe.

Justamente por isso, o encadeamento de reformas pautadas por Haussmann sempre teve também o componente de diferenciação de classe em seu cerne. Como exposto, ao mesmo tempo que reformava a estrutura física da cidade para se adequar a um novo padrão técnico, estético e político (utilizando-se disso, simultaneamente, para dar destino ao capital excedente ocioso e resolver em parte a questão do desemprego urbano), esse projeto marginalizava fisicamente a classe trabalhadora, jogando-a para áreas mais pobres, de menor qualidade estrutural. A partir da ascensão do Estado de Bem-Estar Social, os processos similares realizados ao redor do mundo somavam a esses fatores a ausência de serviços públicos (que, quando lá estavam, não tinham qualidade). Afinal, tendo em mente que o território urbano é tratado como mercadoria pelos capitas, a disponibilidade de serviços públicos de qualidade em um local valoriza-o amplamente ${ }^{21}$. Mas, se as classes mais baixas e a alta burguesia se encontram sob as regras do mesmo direito urbano positivado, por que esta, e não aquelas, consegue as vantagens econômicas e sociais aqui apresentadas? A resposta para essa pergunta, como dito por Marx $^{22}$, está no fato de que,

${ }^{20}$ MARICATO, Ermínia. É a questão urbana, estúpido. Cidades Rebeldes: Passe Livre e as manifestações que tomaram as ruas do Brasil. 1. ed. São Paulo: Boitempo: Carta Maior, 2013, p. 20.

${ }^{21}$ MARICATO, Ermínia. Cidades e Luta de Classes no Brasil. In. Maricato, Ermínia. Para Entender a Crise Urbana. São Paulo: Editora Expressão Popular. 2015. p. 23.

${ }^{22}$ MARX, Karl. O Capital, Livro I. São Paulo: Boitempo Editorial. 2013, p. 309. 
quando os direitos a que estão submetidas é o mesmo, quem determina como as coisas se darão é a força.

Sobre essa segregação espacial com a função clara de diferenciação de classes, podemos tomar o exemplo do Brasil. Ele, enquanto país latino-americano situado na periferia do capitalismo mundial, apresenta uma realidade histórica e econômica pautada na desigualdade social, na escravidão, no colonialismo e na dependência econômica. Grande parte da população urbana vive em áreas ocupadas e afastadas dos centros políticos e econômicos. Essa enorme parcela da população que é segregada política e espacialmente forma o exército de reserva que vende sua força de trabalho para a própria subsistência - vale destacar que essa subsistência não se dá nos moldes da antiguidade ou da modernidade, mas dentro da atual reestruturação dos mecanismos de reprodução do capital, fortemente pautados na economia de consumo. Portanto, o planejamento urbano brasileiro atual possibilita determinar, com mínima margem de erro, quem tem o poder político e econômico a partir da simples localização de sua residência. No entanto, no período colonial, a situação era diferente. Raquel Rolnik explica isso de forma magistral:

Como no burgo medieval, na cidade colonial não existem regiões/trabalho e regiões/moradia, praças da riqueza, praças da miséria. Isto evidentemente não quer dizer que não existiam nestas cidades diferenças de classe ou posição social. Pelo contrário: as distâncias que separavam nobres e plebeus, ricos (...) de pobres (...) eram enormes. Estas distâncias, assim como as distâncias entre senhores e escravos nas cidades brasileiras, não eram físicas. Ricos, nobres, servos, escravos e senhores poderiam estar próximos fisicamente porque as distâncias que os separavam eram expressas de outra forma: estavam no modo de vestir, na gestualidade, na atitude arrogante ou submissa e, no caso brasileiro, também na própria cor da pele. (...) Assim a mistura de brancos e negros nas ruas e nas casas da cidade era possível porque a distância que os 
separava era infinita. $\mathrm{O}$ respeito e hierarquia introduziam a diferença social na vida comunal. ${ }^{23}$

A partir do momento que houve mudança na organização social, com a abolição da escravidão pela Lei Áurea em 13 de Maio de 1888, fez-se necessário também o distanciamento entre essas classes (e raças) para reafirmar a superioridade da burguesia.

Mas esse processo de segregação das classes no ambiente urbano não gerou consequências de âmbito meramente físico, de distanciamento espacial. A não coexistência territorial das classes e a necessidade de reiteração da hierarquia por meio de diferentes espaços físicos dentro de ambientes iguais, inclusive, acabou por aprofundar ainda mais o distanciamento de espectro subjetivo entre esses diferentes estratos sociais. De forma mais clara, a ideia enraizada de que a classe trabalhadora era inferior (inclusive em sua humanidade) à burguesia ganha, a partir disso, contornos espaciais para demarcar essas diferenças. Assim, prega a mentalidade do capital, quanto menos infraestrutura presente em um determinado bairro, proporcionalmente menor é a humanidade e o valor das pessoas ali residentes. Bairros mais pobres, quando (e apenas em casos extremos isso acaba por ocorrer) são visitados, por qualquer motivo que seja, pelas classes mais altas, são vistos como verdadeiros zoológicos humanos, já que as pessoas ali presentes são vistas como animais.

Aqui, é importante ressaltar que, em geral, devido aos processos históricos estabelecidos no Ocidente, esses espaços, assim como no exemplo dado do Brasil, são habitados por negros. Estes, que mesmo gerações depois continuam tendo de arcar com as mazelas da escravidão, foram colocados na base da pirâmide social, sendo os mais pobres dentre os trabalhadores pobres. Do que resultou o fato de que bairros extremamente mal estruturados apresentarem uma predominância de moradores negros. Não é possível discutir as políticas urbanas ignorando as influências do recorte de raça.

Também o recorte de gênero se faz indispensável. Isso porque a formação histórica das sociedades ocidentais, de âmago profundamente machista, reiteradamente determinou os lugares (física e moralmente) adequados e acessíveis, ou não, às mulheres.

${ }^{23}$ ROLNIK, Raquel. O Que é Cidade. São Paulo: Editora Brasiliense. 1988, p. 45-46. 
Em consequência de tudo isso, seguindo a lógica de que não é possível ou aceitável a interação entre representantes de pontos diferentes da hierarquia social, fica cada vez mais presente no imaginário das classes abastadas a ideia de que "a rua é a terra-de-ninguém perigosa, que mistura classes, sexos, (..) posições na hierarquia" 24 .

Consequentemente, entra em cena uma ostensiva cultura do medo em relação ao espaço público das ruas. Cultura do medo essa que continua amplamente atuante nos dias de hoje (mas atingindo já, de forma muito forte, também as classes mais baixas), haja vista a abordagem de caráter absolutamente sensacionalista e violento nos meios de comunicação. Essa cultura do medo, no Brasil, tem em José Luiz Datena seu maior representante, com uma incessante cobertura de crimes bárbaros sendo explicados aos berros pelo apresentador ${ }^{25}$.

Por meio disso, estabelece-se um medo das ruas que reforça o já citado fato de que elas perdem seu caráter público de interação e integração, passando a servir quase que exclusivamente aos interesses do capital.

\section{A CENTRALIDADE ESTRATÉGICA DA CIDADE NAS LUTAS POPULARES}

$\mathrm{O}$ fato de as ruas perderem grande parte de seu caráter público e se tornarem um dos principais instrumentos de domínio pela alienação e pelo fetiche, no entanto, as torna também o espaço mais apropriado para que as lutas sociais se estabeleçam. Por isso, a apropriação dos espaços públicos, das ruas e das praças, acontece como o principal meio de instrumento de enfrentamento ao sistema e reivindicação de direitos. Fato amplamente verificável pela facilidade com que se associam diversas lutas, nos últimos séculos, a espaços públicos sob controle (direto ou indireto) das classes dominantes: a Primavera Árabe que, entre outros espaços, trouxe grande destaque à ocupação da Praça Tahrir no Egito, por mais de um milhão de pessoas em 2011, em busca de democracia real no

\footnotetext{
${ }^{24}$ ROLNIK, Raquel. O Que é Cidade. São Paulo: Editora Brasiliense. 1988, p. 50.

${ }^{25}$ Também é possível ver uma caracterização interessante dessa cultura por meio do personagem de Samuel L. Jackson na versão de Robocop dirigida por José Padilha em 2014.
} 
Egito e no mundo árabe; o movimento de tomada da praça de Wall Street, centro do capitalismo financeiro global, pelos "99\%", contra a desigualdade econômica e social; os protestos massivos que tiveram como local a Praça da Sé e a Cinelândia no processo das Diretas Já, no Brasil, na primeira metade da década de 80; as marchas organizadas por Martin Luther King de Selma a Montgomery reivindicando o direito ao voto para a população negra norteamericana; os intensos protestos urbanos por todo os EUA que forçaram o término da Guerra do Vietnã; até mesmo a tomada das ruas, do porto e das águas de Odessa no apoio à revolta dos marinheiros do Encouraçado Potemkin, em 1905 (como belamente retratado por Sergei M. Eisenstein no filme de 1925 que leva o nome da embarcação); ou, também, as regulares manifestações populares em espaços públicos na França a partir de 31 de março de 2016, que têm sido chamadas de Nuit Debout, que questionam veementemente o sistema político e econômico vigente no mundo contemporâneo. Não faltam exemplos que demonstram a força e a centralidade estratégica do espaço das ruas na luta por mais direitos e contra a doutrina do capital.

$\mathrm{Na}$ passeata, comício ou barricada a vontade dos cidadãos desafia o poder urbano através da apropriação simbólica do terreno público. Nestes momentos, assim como nas festas populares como o carnaval ou as festas religiosas, as muralhas invisíveis que regulam a cidade, mantendo cada coisa em seu lugar e comprimindo a multidão do diaa-dia, se salientam pela ausência. Quando o território da opressão vira cenário de festa, é a comunidade urbana que se manifesta como é: com suas divisões, hierarquias e conflitos, assim como com suas solidariedades e alianças. ${ }^{26}$

Como na dialética hegeliana: o urbano, ao se apresentar enquanto elemento fundamental para a manutenção e propagação do capitalismo, local onde as contradições (de classe, raça e gênero, é importante reiterar) desse modelo atingem o máximo de sua intensidade, traz em si o gérmen da superação desse sistema. Por isso, é certeiro David Harvey ao afirmar

${ }^{26}$ ROLNIK, Raquel. O Que é Cidade. São Paulo: Editora Brasiliense. 1988, p. 25. 
que "Lefebvre estava certo ao insistir que a revolução tem de ser urbana, no sentido mais amplo deste termo, ou nada mais" 27.

\section{CONSIDERAÇÕES FINAIS}

Para a superação dos problemas apresentados ao longo do texto, faz-se necessária não somente a ampliação do conteúdo entendido como direito à cidade, mas a superação do atual paradigma de planejamento urbano, que é inerentemente concebido enquanto projeto de consolidação da reprodução do capitalismo, trazendo consigo a precarização do trabalho e das próprias condições de vida e de reprodução alienada da classe trabalhadora.

É preciso reformular a lógica de estruturação e reprodução dos espaços público e privado, tirando das "ruas" seu forte caráter de alienação e de fetichismo. Nesse sentido, compreende-se que a apropriação do espaço público pela população é revolucionária, uma vez que a diversidade de experiências e consciências de classes causa uma tensão dialética que contribui para a retomada da consciência dos espaços públicos enquanto espaços políticos.

Alguns movimentos sociais e populares têm avançado bastante nessa pauta de uma nova política urbana. Esses movimentos buscam criar um novo paradigma jurídico e institucional para as cidades. Através da mobilização dos movimentos sociais e populares, no Brasil, foram conquistados, por exemplo: o Ministério das Cidades (2003); o Conselho das Cidades (2004); diversas Conferências Nacionais das Cidades (2003, 2005 e 2007) e a aprovação da lei n. 10.257/2001, mais conhecida como Estatuto da Cidade.

No entanto, a agenda da reforma urbana e fundiária foi deixada de lado nos últimos anos. A propriedade urbana se concentra nas mãos de poucos proprietários detentores do capital imobiliário. A legislação foi flexibilizada para atender a esses interesses e a disputa pela propriedade numa perspectiva de moradia para a classe trabalhadora e de geradora de lucro para as elites - entre o capital imobiliário e a classe trabalhadora obrigou a grande maioria da população a ocupar a periferia da periferia;

${ }^{27}$ HARVEY, David. O Direito à Cidade. In Revista Lutas Sociais. São Paulo, $\mathrm{n}^{\mathrm{o}} 29$, p. 88. 
onde não há saneamento, urbanização, mobilidade urbana, nem qualquer outro aparelho do Estado. Ou seja, a periferia acabou se configurando como uma "cidade ilegal", onde o Estado e os direitos não têm alcance.

É importante ressaltar que, no modelo de civilização que está posto, o Estado e o próprio Direito, enquanto intrinsecamente defensores do capitalismo, como apontado por Marx, não apenas não são suficientes para que se possa partir para uma nova concepção de urbano e de sociedade, como também atrapalham que isso se concretize. Isso não descarta ambos como instrumentos de melhoria na situação real da classe trabalhadora, inclusive dando possibilidade material para a concretização da utopia de uma nova civilização.

Para que a utopia, pela perspectiva de Ernst Bloch, seja alcançável, fazem-se necessárias as condições favoráveis a ela também no plano concreto. Análise esta que se apresenta já desde Engels ${ }^{28}$.

(...) Engels reclama, para si e para Marx, não uma negação da utopia, mas o seu afastamento, enquanto ciência encerrada em si mesma, de especulação do futuro melhor. Para cumprir os propósitos da utopia, seria preciso destruir o método utópico. ${ }^{29}$

Portanto, a movimentação por efetivação dos direitos urbanos positivados se faz indispensável para a melhora de condição de vida da população. Mas em momento algum pode ser deixada de lado a utopia por uma nova cidade e uma nova civilização, que traga em si uma forma original de encarar o urbano, e, consequentemente, retomando Robert Park, a vida e as relações pessoais.

Ou se define "personalidade" e "individualidade" em termos de suas possibilidades dentro da forma estabelecida de civilização, em cujo caso a sua realização é sinônimo, para a grande maioria, de um

${ }^{28}$ ENGELS, Friedrich. Do socialismo utópico ao socialismo científico. In Marx, Karl e Engels, Friedrich. Obras escolhidas. Vol. 2. São Paulo, AlfaÔmega, s/d. p. 332.

${ }^{29}$ MASCARO, Alysson Leandro. Utopia e Direito: Ernst Bloch e a Ontologia Jurídica da Utopia. São Paulo: Quartier Latin, 2008. p. 54. 
ajustamento bem sucedido; ou se define nos termos de seu conteúdo transcendente, incluindo suas potencialidades socialmente negadas, para além (e subentendidas) de sua existência concreta; neste caso, sua realização implicaria transgressão, além da forma estabelecida de civilização, para modos radicalmente novos de "personalidade" e "individualidade" incompatíveis com os prevalecentes. Hoje, isso significaria "curar" o paciente para converter-se num rebelde ou (o que quer dizer a mesma coisa) num mártir. ${ }^{30}$

\section{REFERÊNCIAS BIBLIOGRÁFICAS}

BENJAMIN, Walter. Paris, Capital do Século XIX. In Textos de Walter Benjamin. Trad. Flavio R. Kothe. Disponível em: $<$ https://teoriadoespacourbano.files.wordpress.com/2013/03/benja min-w-paris-capital-do-sc3a9culo-xix-trad-kothe.pdf $>$.

EAGLETON, T. "Awakenig from modernity", Times Literary Suplement, 20 de fevereiro de 1987.

ENGELS, Friedrich. Do socialismo utópico ao socialismo científico. In Marx, Karl e Engels, Friedrich. Obras escolhidas. Vol. 2. São Paulo, Alfa-Ômega, s/d.

. Sobre a Questão da Moradia. $1^{a}$ ed. São Paulo: Boitempo Editorial. 2015.

HARVEY, David. A liberdade da cidade. Cidades Rebeldes: Passe Livre e as manifestações que tomaram as ruas do Brasil. 1. ed. São Paulo: Boitempo: Carta Maior, 2013. Condição pós-moderna (1989). São Paulo: Loyola, 1993.

O Direito à Cidade. In Revista Lutas Sociais. São Paulo, no 29.

O Trabalho, o capital e o conflito de classes em torno do ambiente construído nas sociedades capitalistas avançadas. In Temas Urbanos e Regionais. Disponível em: $<$ https://antropologiadeoutraforma.files.wordpress.com/2014/03/da vid-harvey-o-trabalho-o-capital-e-harvey-david-o-conflito-de-

${ }^{30}$ Marcuse, Hebert. Eros e Civilização. Rio de Janeiro, Guanabara Koogan, s/d, p. 220. 
classes-em-torno-do-ambiente-construc3addo-nas-sociedadescapitalistas-avanc3a7adas.pdf $>$.

Maria Rita Kehl: Por uma cidade sem carros! - Durante o seminário Cidades Rebeldes - disponível em: $<$ https://www.youtube.com/watch?v=28Mf1nO2kYY>.

MARICATO, Ermínia. É a questão urbana, estúpido. Cidades Rebeldes: Passe Livre e as manifestações que tomaram as ruas do Brasil. 1. ed. São Paulo: Boitempo: Carta Maior, 2013.

. Cidades e Luta de Classes no Brasil. In. Maricato, Ermínia. Para Entender a Crise Urbana. p. 23. São Paulo: Editora Expressão Popular. 2015.

MARX, Karl. O Capital, Livro I. São Paulo: Boitempo Editorial. 2013.

MARCUSE, Hebert. Eros e Civilização. Rio de Janeiro, Guanabara Koogan, s/d.

MASCARO, Alysson Leandro. Utopia e Direito: Ernst Bloch e a Ontologia Jurídica da Utopia. São Paulo: Quartier Latin, 2008.

PARK, Robert. On Social Control and Collective Behavior. Chicago, Chicago University Press, 1967.

RABAN, Jonathan. Soft city. Londres: 1974.

ROLNIK, Raquel. O Que é Cidade. São Paulo: Editora Brasiliense. 1988.

SANTOS NETO, Artur Bispo dos. A Interpretação Alegórica do mundo na Filosofia de Walter Benjamin. Disponível em: $<$ https://books.google.com.br/books?id=Hm87AsJwPxgC\&printsec $=$ frontcover\&hl=pt-

$\mathrm{BR} \&$ source $=\mathrm{gbs}$ ge_summary_r$\& \mathrm{cad}=0 \# \mathrm{v}=$ onepage $\& \mathrm{q} \& \mathrm{f}=$ false $>$. 
